\title{
Mina do Morro do Ouro, Apiaí, SP - A transformação em parque
}

\author{
Morro do Ouro Gold Mine, Apiaí, SP - Transformation into a park \\ HÉLIO SHIMADA \\ Instituto Geológico - SMA, São Paulo - helio.shimada@gmail.com
}

\begin{abstract}
Resumo
A extração de ouro em depósitos secundários em Apiaí, no sul do Estado de São Paulo, foi iniciada na segunda metade do século 17, sendo realizada de maneira descontínua até meados do século 19. A mineração subterrânea na mina do Morro do Ouro foi iniciada em 1889, funcionando de maneira intermitente até 1942, quando foi paralisada compulsoriamente, e não mais voltou a operar. Em 1998, após longo tempo de abandono, foi transformada em área de utilidade pública por meio de lei municipal. Em 2002, foi elaborada proposta para a conversão da mina abandonada em atrativo turístico, aproveitando as galerias ainda preservadas e as ruínas do beneficiamento. A proposta foi aceita pelo município, que iniciou a efetiva implantação do parque em 2003. Em 2004, foi oficialmente criado o Parque Natural Municipal do Morro do Ouro, caracterizando a conversão de um passivo ambiental em sítio geoturístico.
\end{abstract}

Palavras-chave: Morro do Ouro; Apiaí; mina de ouro; geoturismo; parque natural.

\begin{abstract}
The exploitation of gold in secondary deposits started in Apiaí in the second half of the 17th century, and was discontinuously performed until the end of the 19th century. The underground mining was initiated in 1889 in the Morro do Ouro mine and operated intermittently until 1942, when it was compulsorily closed, not operating since them. In 1998, after being abandoned for a long time, it turned into an area of public interest by a municipal law. In 2002, a proposal to turn the former mine into a geotouristic attraction was accepted by the municipality wich started the effective set up of the park in 2003. In 2004, the Parque Natural Municipal do Morro do Ouro was officially created, characterizing the conversion of an environmental liability into a geotouristic site.
\end{abstract}

Keywords: Morro do Ouro; Apiai; gold mine; geotourism; nature park

\section{Introdução}

O presente texto apresenta o Parque Natural Municipal do Morro do Ouro (PNMMO), em Apiaí, SP, criado numa mina abandonada de ouro, convertendo um passivo ambiental em importante sítio geoturístico. São abordados o contexto geológico da mineralização aurífera, o histórico da mineração no Morro do Ouro, o processo de criação do PNMMO e as considerações sobre seu futuro e as possibilidades de outras iniciativas similares na região.

\section{Localização}

O PNMMO localiza-se imediatamente a leste da zona urbana de Apiaí (Figuras 1 e 2), no divisor de águas das bacias dos rios Ribeira de Iguape e Paranapanema.
O acesso, partindo de São Paulo, pode ser feito pelo seguinte roteiro: rodovia Castelo Branco (SP-280) até Tatuí; rodovia Tatuí - Itapetininga (SP-127), e rodovia Itapetinga - Apiaí (SP-250). Uma outra opção de acesso, a partir de São Paulo, é a rodovia Regis Bittencourt (BR116) até Jacupiranga; rodovia Jacupiranga - Eldorado (SP193); e rodovia Eldorado - Apiaí (SP-165) passando por Iporanga, com o trecho até Apiaí ainda não pavimentado.

Partindo de Curitiba, o roteiro de acesso é: rodovia Curitiba - Adrianópolis (PR-476) e rodovia Ribeira - Apiaí (SP-250). Opcionalmente, há o acesso via Jacupiranga, como acima descrito. 


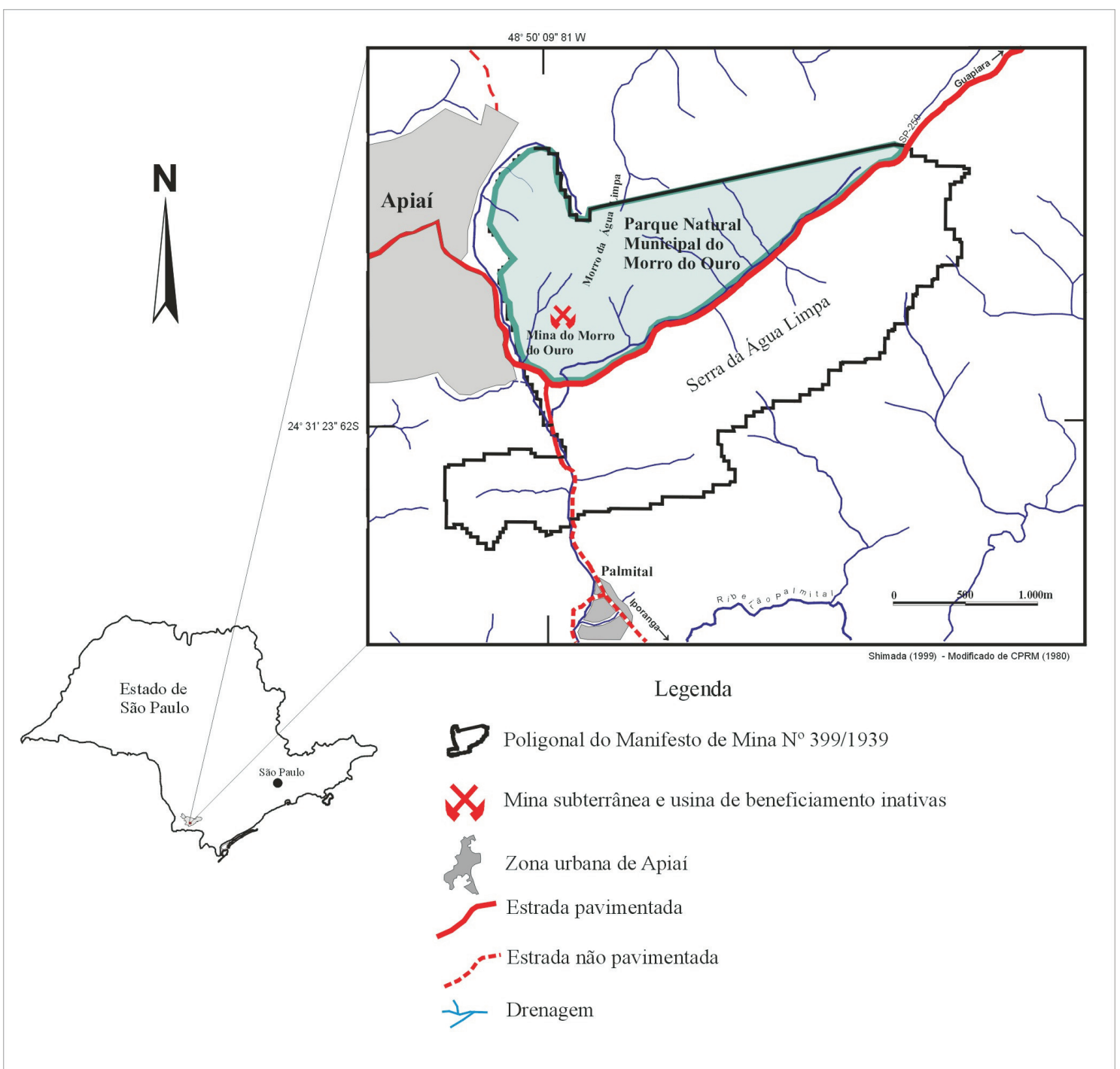

Figura 1 - Localização do Parque Natural Municipal do Morro do Ouro.

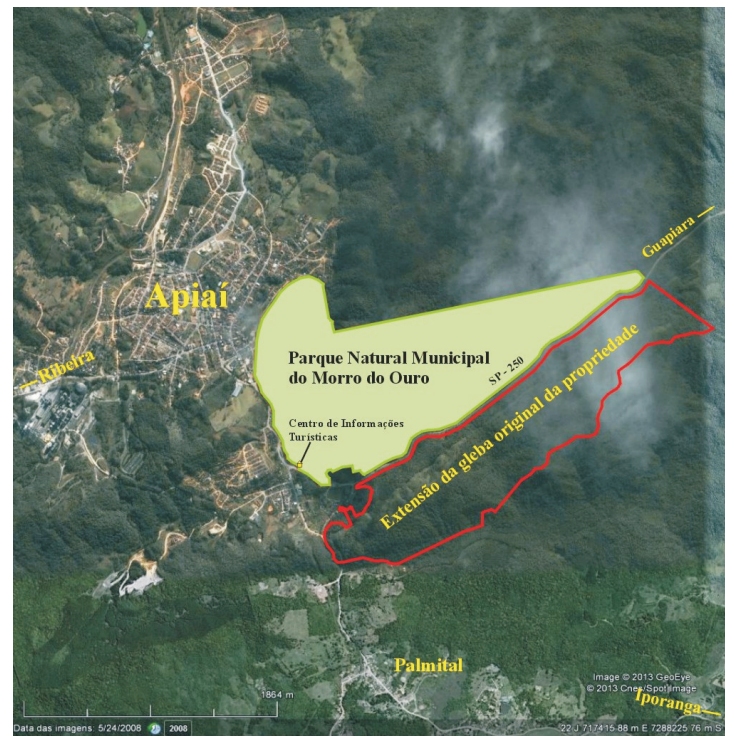

Figura 2 - O Parque Natural Municipal do Morro do Ouro em imagem do Google Earth. 


\section{Contexto geológico da mina do Morro do Ouro}

A região da mina do Morro do Ouro está situada no alto Vale do Ribeira, no largo segmento crustal denominado Cinturão Ribeira, com cerca de 2.500 km de extensão e constituindo parte do Sistema Orogênico Mantiqueira (Brito Neves et al., 1999). O Cinturão Ribeira, paralelo à linha da costa sudeste, é cortado por um sistema de zonas de cisalhamentos transcorrentes dextrais, relacionado às colisões oblíquas entre os crátons São Francisco, Congo, Luís Alves e Paranapanema durante o Neoproterozóico (Campanha \& Sadowski, 1999; Faleiros et al., 2011). No Neoproterozóico, durante a Orogenia Brasiliano/Pan-Africana, esse segmento crustal foi amalgamado, deformado e metamorfizado (Heilbron et al., 2004; Faleiros et al., 2011; Siga Junior et al., 2009, 2011; Campanha et al. 2008a, b). Vários autores realizaram trabalhos de caráter regional no Vale do Ribeira, entre os quais podem ser citados Campanha (1991), Daitx (1996), Fassbinder (1996) e Faleiros (2008). A porção sul do Cinturão Ribeira abrange, de norte para sul, os terrenos compostos Apiaí, Curitiba e Luís Alves, delimitados pelas zonas de cisalhamento Lancinha e Serra do Azeite. O Terreno Apiaí, onde está situado o Morro do Ouro (Figura 3), é composto por sequências de rochas supracrustais de baixo a médio grau metamórfico, originalmente designadas como Grupo Açungui, posteriormente elevado à categoria de Supergrupo (Campanha, 1991; Campanha \& Sadowski, 1999). A região foi também objeto de vários projetos de mapeamento geológico e trabalhos avulsos como os executados pela CPRM (1981) e Chiodi Filho (1984).

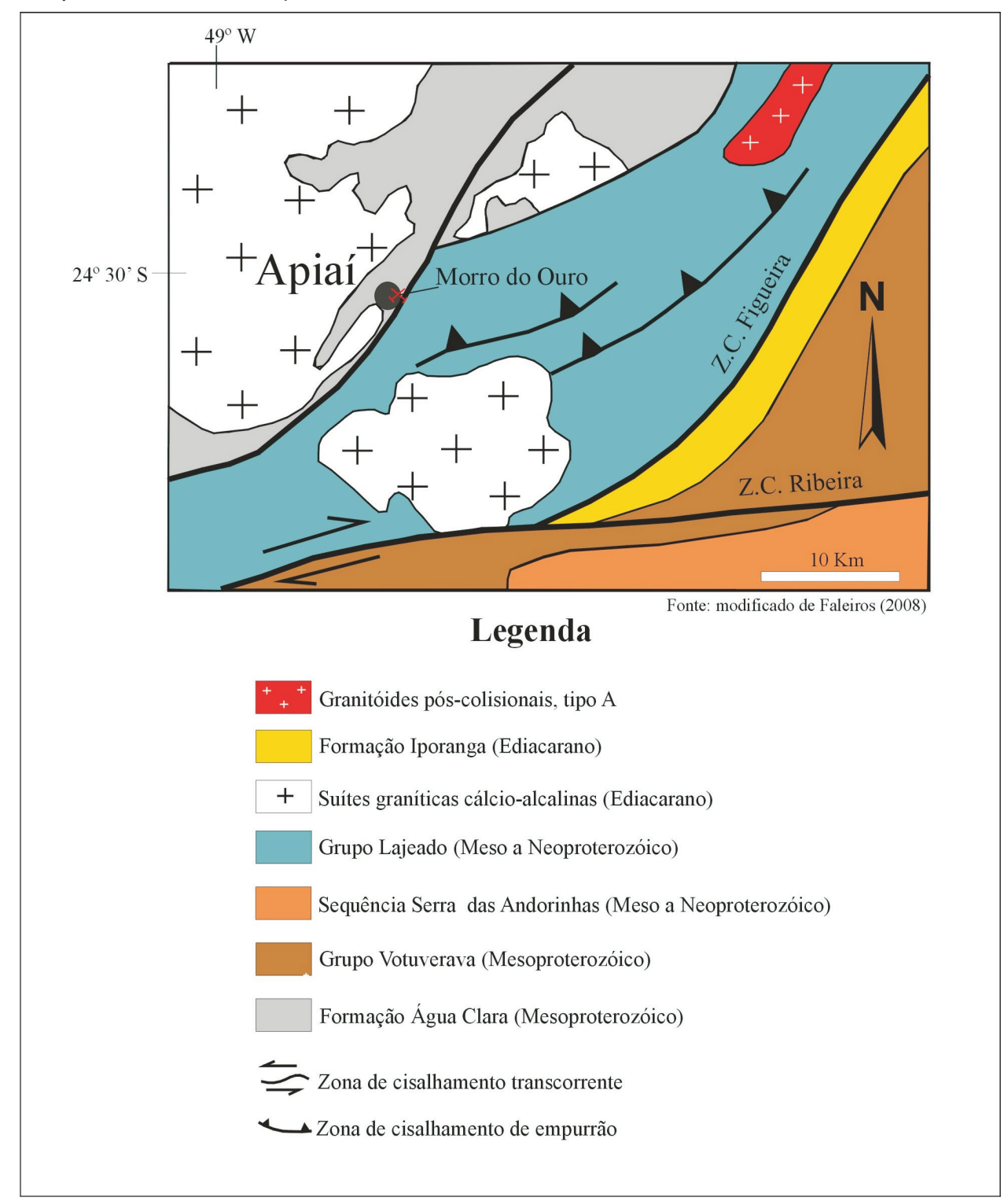

Figura 3-Contexto geológico da região de Apiaí. 
No Morro do Ouro, predominam as rochas metamórficas de baixo grau da Formação Água Clara (Figura 5), com a predominância de xistos variados com intercalações de calcários, filitos, dolomitos, rochas calciossilicáticas e quartzitos. As mineralizações auríferas do Morro do Ouro ocorrem em dois tipos de minério: veios de quartzo escuro (Figura 4) cortando rochas metassedimentares de fácies xisto verde da Formação Água Clara (ca. 1450 - 1500 Ma; Weber et al., 2004) e minério limonítico, formado por quarztito (possivelmente chert recristalizado) enriquecido em óxidos de ferro e intercalado com níveis de limonita (Paiva e Morgental, 1980) (Figura 6). Nos veios, o ouro está contido nas estruturas cristalinas dos sulfetos metálicos de ferro e cobre que, quando oxidados, apresentam o ouro na forma livre, em partículas de dimensões variadas. No minério limonítico, o ouro livre está associado aos óxidos presentes.

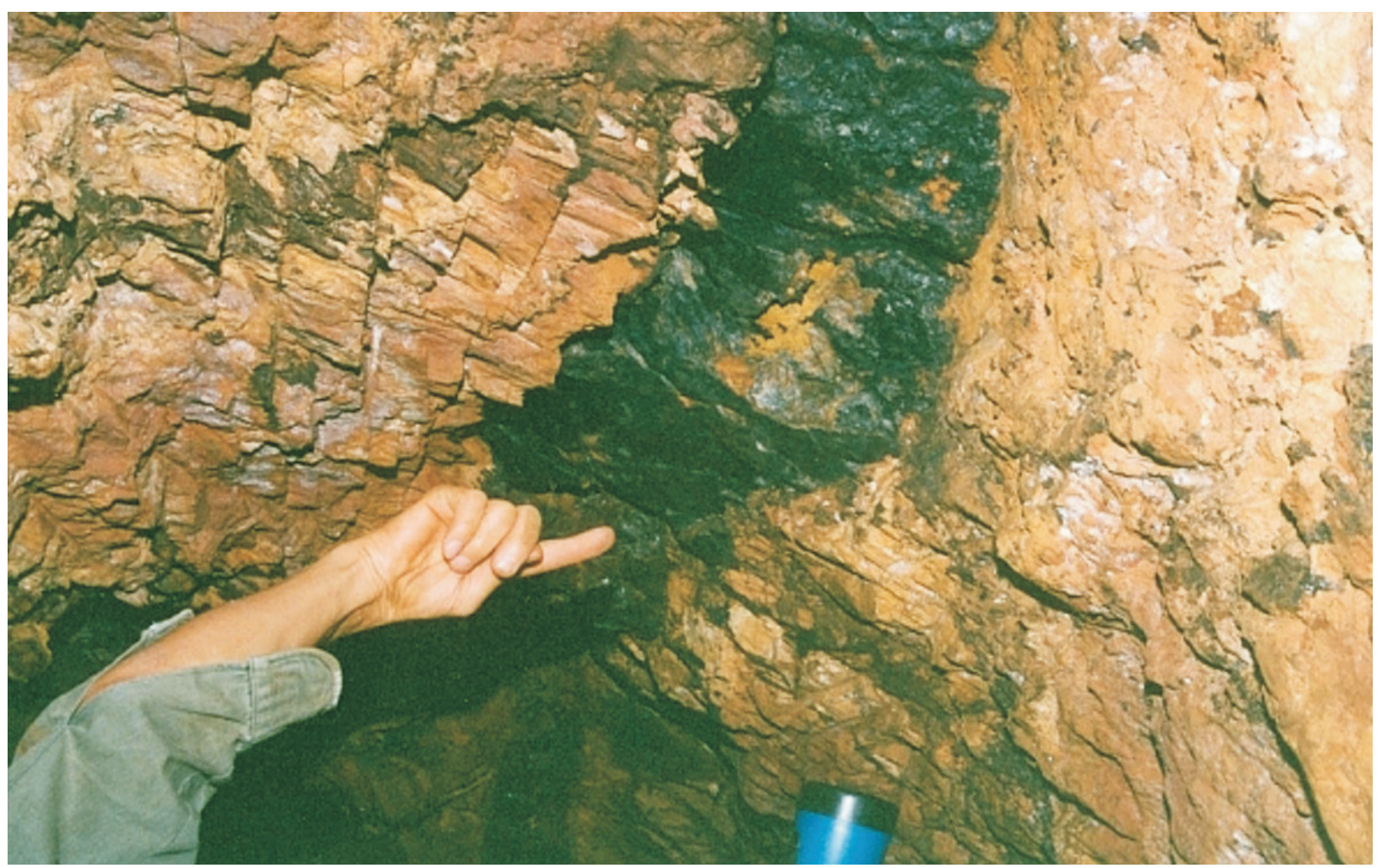

Figura 4-Veio de quartzo aurífero no teto do túnel T-15.

Faleiros (2012) estudou os regimes de fluidos hidrotermais e a formação dos veios de quartzo aurífero do Morro do Ouro, identificando dois sistemas: veios NW extensionais subverticais e veios NE subverticais paralelos aos planos axiais de dobras apertadas. Os primeiros foram formados sob pressão de fluidos litostática a supralitostática (110 - $225 \mathrm{MPa}$ a 225 C), e os últimos foram formados sob pressão de fluidos próxima a valores hidrostáticos (55- $80 \mathrm{MPa}$ e a 225을. Os dois tipos de veios apresentam inclusões fluidas dos sistemas $\mathrm{CO}_{2}-\mathrm{CH}_{4}$ e $\mathrm{H}_{2} \mathrm{O}-\mathrm{CO}_{2}-\mathrm{CH}_{4}-\mathrm{NaCl}-\mathrm{CaCl}_{2}$, com salinidades variando de 4 a $67 \%$ em peso de $\mathrm{NaCl}$ equivalente.
A mesma autora sugere que os veios mineralizados podem estar relacionados à falha do Carumbé, transcorrente dextral de direção NE, adjacente ao Morro do Ouro, que teria atuado como falha-válvula. Os fluidos hidrotermais em interação com as rochas encaixantes foram, provavelmente, enriquecidos em ouro nelas contido, ocorrendo a posterior precipitação devido às alterações nas condições físico-químicas dos fluidos. Tais variações ocorreram como consequência de flutuações cíclicas na pressão dos fluidos e do regime tectônico associado a episódios de atividades sísmicas relacionadas à falha. 


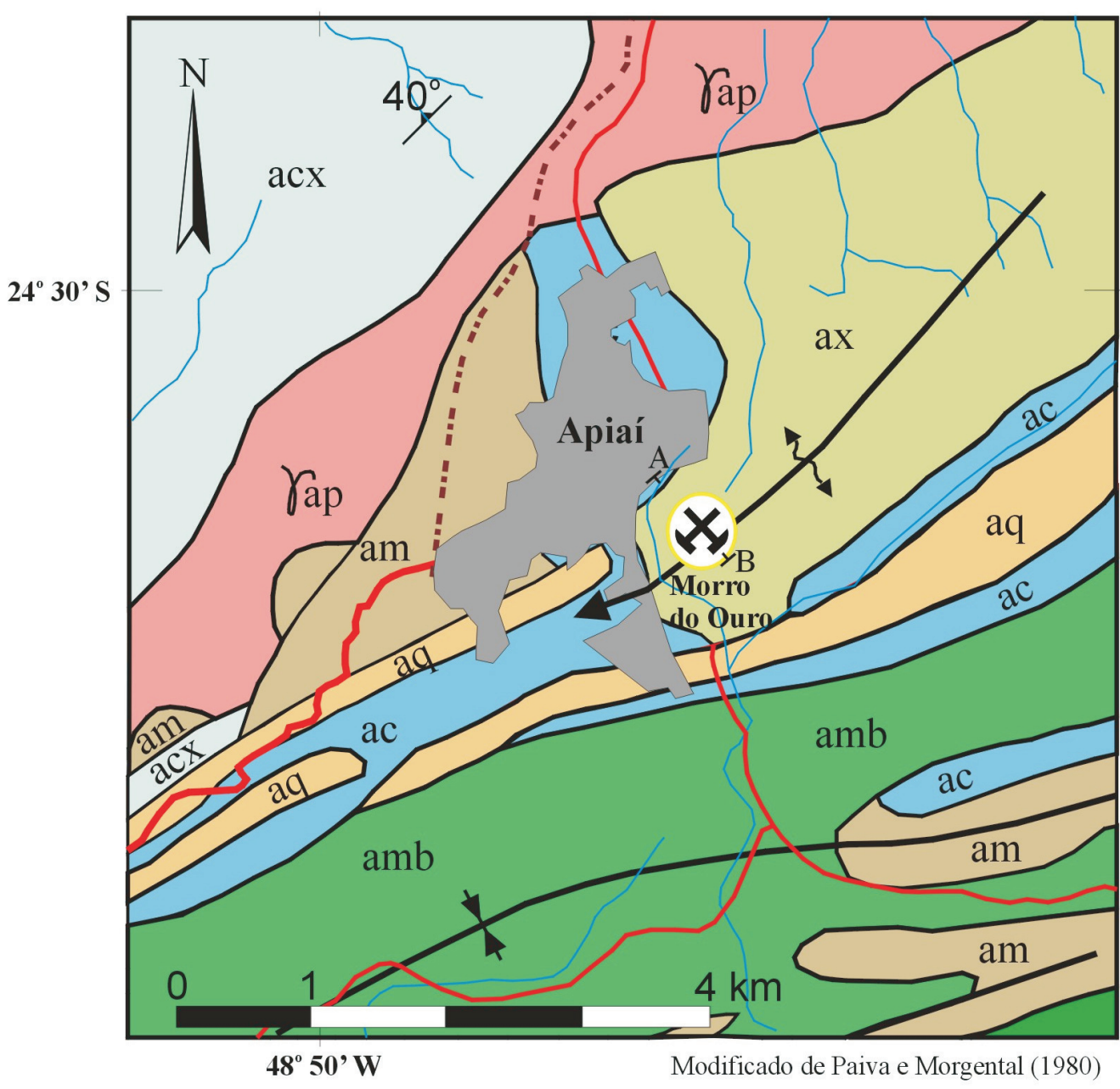

Yap Rochas granitóides embrechíticas, sin a tardicinemáticas brasilianas e indiferenciadas

\section{Supergrupo Açungui}

am

Metassedimentos síltico-argilosos, incluindo metarritmitos

ac

Quartzitos, metarenitos e metarcósios

$\mathrm{ac}$

ax

$\operatorname{acx}$

$\mathrm{amb}$
Epicalcários calcíticos

Micaxistos com intercalações de metagrauvacas, filitos e quartzitos subordinados.

Micaxistos com interclações de epicalcários, quartzo-mica xistos e calco-hornfels.

Metabasitos, incluindo anfibolitos inseparáveis
Anticlinório com caimento de eixo indicado

Sinclinal sem caimento de eixo indicado

Estrada

$-\ldots$ Ferrovia

7 Drenagem

Figura 5-Mapa geológico simplificado da área do Morro do Ouro. 


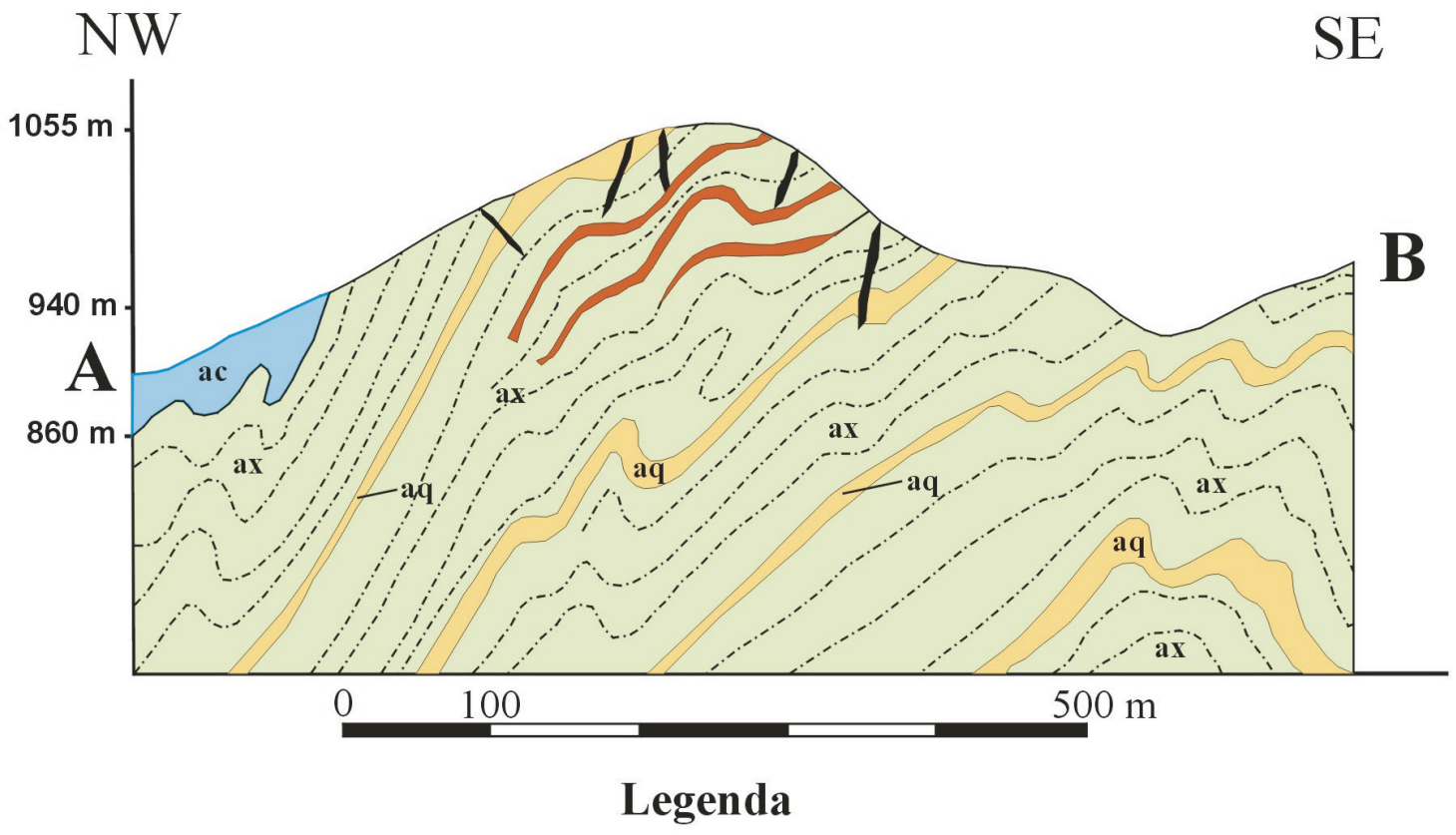

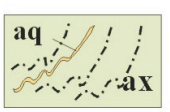

Micaxistos (ax) com intercalações de filitos, metagrauvas e quartzitos (aq) subordinados

ac

Epicalcários calcíticos

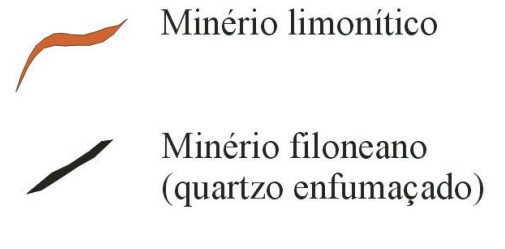

Modificado de Paiva e Morgental (1980)

Figura 6 - Perfil geológico esquemático A-B (NW-SE) da área do Morro do Ouro.

\section{Breve histórico da mina do Morro do Ouro}

As mineralizações auríferas do Morro do Ouro são conhecidas, segundo Calazans (1996), desde a segunda metade do século 17, quando aventureiros em busca de ouro, partindo de Iguape, subiram o rio Ribeira de Iguape até o local então denominado Porto de Apiahy, a jusante de Itaóca. Sánchez (1984) cita como possível a descoberta no ano de 1675. Desse local, alcançaram os ribeirões com cascalho aurífero nos arredores da cidade atual. O número de garimpeiros aumentou rapidamente, instalando-se o povoado em Vila Velha do Peão, a norte do Morro do Ouro. Este passou a ser vasculhado pelos mineradores por volta do ano de 1770, em busca de minérios coluviais e eluviais. Na área a oeste do morro surgiu o povoado de Santo Antonio das Minas de Apiahy, elevado à categoria de vila em 14 de agosto de 1771 . Foi o 19 povoado paulista a se tornar município; porém, sua emancipação consolidou-se somente em 6 de agosto de 1797, sendo elevado a comarca em 7 de janeiro de 1937.
Após a exaustão das reservas de minério secundário superficial, foi iniciada a lavra subterrânea do minério primário no Morro do Ouro, que funcionou de maneira intermitente entre 1889 e 1942 . Neste ano, foi paralisada de maneira compulsória pelo governo federal devido ao fato de a mina ser operada por uma empresa japonesa, permanecendo a mina paralisada e abandonada até o início dos anos 2000. Paiva e Morgental (1980) sintetizaram cronologicamente os fatos relevantes relacionados à mina do Morro do Ouro:

1885 - A empresa Resende \& Cia. incumbiu o Eng. Gonzaga de Campos a realizar pesquisa na zona de Apiaí, tendo sido a propriedade do Morro do Ouro, considerada a mais importante entre as estudadas.

1889 - José de Souza organizou uma sociedade, instalando pilões de madeira com sapatas de aço para trituração do minério, construindo também uma estrada de carros de boi subindo o morro.

1902 - Antonio Carlos Melchert constituiu, com alguns amigos, a empresa Antonio Melchert \& Cia., montando 
um sistema de dez pilões e completo equipamento para amalgamação e cianetação. A iniciativa não produziu os resultados esperados, sendo paralisada em 1904, limitando-se os trabalhos às pesquisas em pequena escala até o ano de 1910.

1910 - David Carlos MacKnight, Frank Edward Krug e Walter Charnley obtiveram uma opção para estudar a jazida e oportunamente constituir uma empresa mineradora. Planejando operações conjuntas com as instalações de Melchert, encomendaram um moinho com capacidade de 50 toneladas diárias; porém, a morte súbita do último motivou o fracasso do empreendimento. O maquinário ficou depositado em Itapeva (então Faxina) até 1922.

1922 - Macknight e seus sócios adquiriram as propriedades do Morro do Ouro e Água Limpa. No mesmo ano, um incêndio destruiu as instalações de Melchert. Mesmo assim, o grupo continuou a lavra do minério, abrindo $1.600 \mathrm{~m}$ de galerias e recuperando 6,5 kg de ouro através de amalgamação até o ano de 1924. 0 metal recuperado tinha $76 \%$ de ouro e $24 \%$ de prata.

1939 - Com o advento do Código de Minas, em 1934, MacKnight, Krug e Charnley conseguiram o Manifesto de Mina sob registro no 399, em 20 de abril de 1939. A mina e seus imóveis estavam então arrendados, desde 16 de março de 1939, à Cia. de Mineração de Apiaí, com participação de capital japonês, pelo prazo de 15 anos com opção para outros 15. A atividade dessa empresa foi autorizada pelo Decreto no 5.021 de 13 de dezembro de 1939, dando-se início imediato aos trabalhos. No prazo de um ano, foram abertos $2.500 \mathrm{~m}$ de galerias, das quais saíram cerca de 10.000 t de minério a um teor médio de 5 $\mathrm{g} / \mathrm{t}$. Na época, as reservas da jazida foram estimadas em 100.000 toneladas de minério. $O$ tratamento do minério consistia em britagem, moagem, e recuperação do ouro grosso por amalgamação com mercúrio. O ouro fino era recuperado por cianetação, onde o metal era dissolvido em solução de cianeto de sódio e, após filtragem, recuperado por precipitação com adição de zinco.

1942 - Com o início da segunda guerra mundial, a mina foi paralisada por força do Decreto Lei no 4.166, que determinou o confisco dos bens dos súditos do Eixo Alemanha - Itália - Japão, sendo nomeados interventores.

1945 - Ordem de liquidação extra-judicial da empresa.

1960 - A União reconhece que os legítimos donos da empresa não eram súditos do Eixo, devolvendo o remanescente do empreendimento à Cia. de Mineração de Apiaí. Porém, a longa paralisação havia provocado o colapso no sistema subterrâneo de galerias, inviabilizando o reinício da lavra conforme o plano original. Somando-se a isso as condições desfavoráveis do mercado do ouro na época, a empresa considerou inviável um novo planejamento de lavra.

Paiva e Morgental (1980) estimaram a reserva remanescente de minério, para os dois tipos citados e acima da cota $860 \mathrm{~m}$, em 1.040.000 t de minério, com teor médio ponderado de $2,58 \mathrm{~g} / \mathrm{t}$ de ouro. A estimativa admitiu a extensão do minério ao Morro da Água Limpa.

\section{A criação do Parque Natural Municipal do Morro do Ouro}

Em 28 de maio de 1998, a lei municipal de autoria do então vereador Donizetti Borges Barbosa transformou o Morro do Ouro em área de utilidade pública, inicialmente visando apenas preservar os mananciais da cidade. Shimada (2002) observou que as ruínas das instalações de beneficiamento poderiam ser recuperadas e algumas galerias ainda permitem acesso seguro, exibindo as mineralizações auríferas, e propôs à prefeitura de Apiaí o aproveitamento geoturístico da mina do Morro do Ouro, nos moldes de iniciativas similares que conheceu no exterior. A proposta foi aceita pela prefeitura, decidindose pela criação de um parque natural municipal. $\mathrm{Na}$ época, a propriedade do terreno ainda era privada, constituindo obstáculo para o projeto. Em 2003, a empresa Camargo Corrêa Cimentos, que opera fábrica na cidade, adquiriu o terreno, doando-o à prefeitura. Assim, teve início a efetiva implantação do parque, oficializada pelo Decreto Municipal 003/2004. Atualmente, o Parque Natural Municipal do Morro do Ouro, em área de cerca de 450 hectares, recebe constantes melhorias na infraestrutura e conta também com trilhas de caminhada e um Centro de Informações Turísticas que funciona 24 horas/dia, todos os dias da semana, inclusive feriados (Figura 7), transformando-se em destacado atrativo geoturístico e de educação ambiental da região, descrito por Shimada (2008).

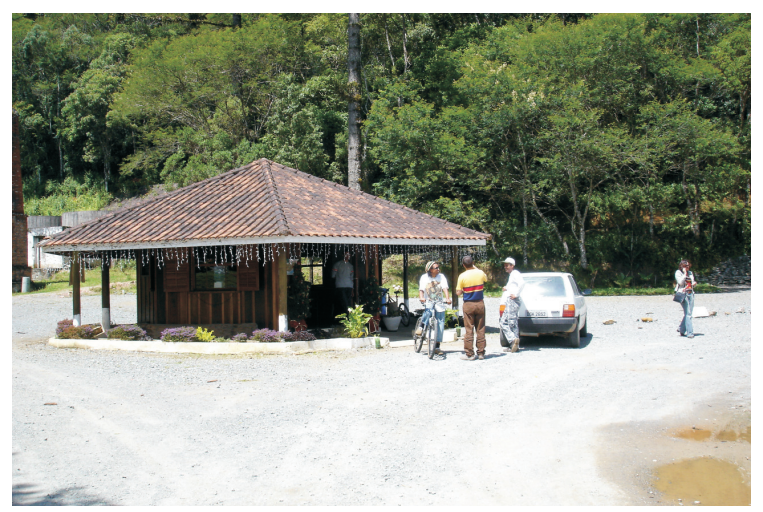

Figura 7-CIT - Centro de Informações Turísticas do PNMMO

O PNMMO constitui o primeiro dos atrativos relacionados à história da mineração na região, cujo início remonta ao século 17 , mas tem sido pouco valorizado. Nesse contexto, Silva \& Shimada (1997) e Shimada et al. (1998) já haviam estudado as minas abandonadas de chumbo e prata da região, propondo a recuperação e aproveitamento geoturístico desses sítios, compondo o "Roteiro das Minas" regional. Os variados atrativos naturais da região, aliados a esse roteiro, resgatariam a rica história da mineração e seria mais uma 
interessante opção para os visitantes.

No PNMMO, complementando a infraestrutura externa de recepção de visitantes e da recuperação das instalações de beneficiamento (Figura 9), foi proposta a melhoria das condições do túnel T-15 (Figura 8), o mais bem preservado, onde é possível implantar um roteiro de visitação que permite a observação das mineralizações. Para tanto, foi contratada a consultoria de um Engenheiro de Minas, que elaborou relatório propondo medidas de segurança nas galerias (Figura 10), como interdições de trechos perigosos, aberturas de saídas de emergência e escoramentos localizados.

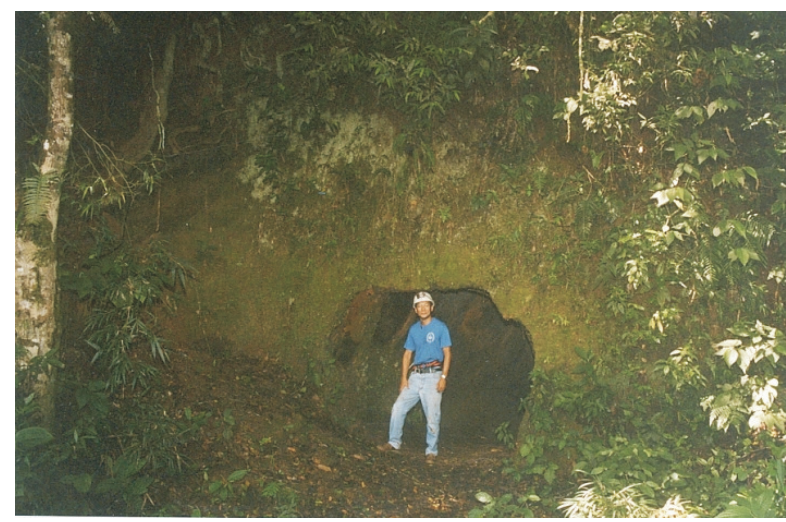

Figura 8-Uma das entradas do túnel T-15

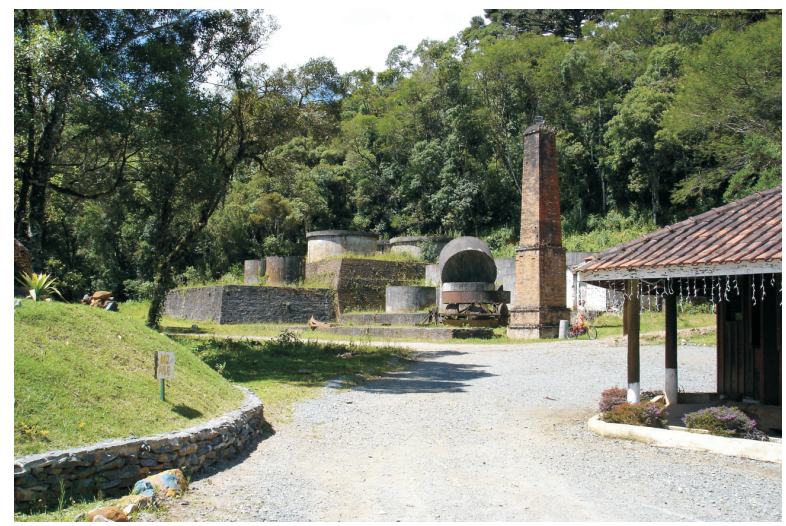

Figura 9 - Ruínas das instalações de beneficiamento, próximas ao CIT

Paralelamente, foi proposto o mapeamento detalhado dos demais túneis do Morro do Ouro, para seleção daqueles mais adequados para potencial aproveitamento geoturístico.

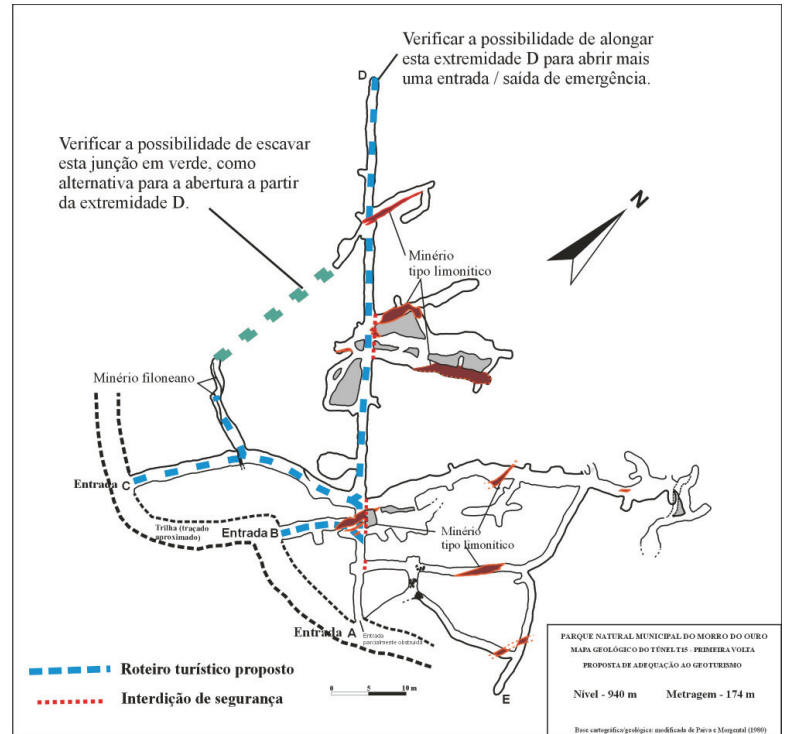

Figura 10 - Proposta de adequaçãodo túnel T-15 da mina do Morro de Ouro ao geoturismo.

O acesso seguro às galerias da antiga mina não proporcionaria apenas atrativo para os turistas, mas também de pesquisadores interessados em estudos da mineralização aurífera, como os realizados por Faleiros (2012).

\section{Considerações finais}

O Parque Natural Municipal do Morro do Ouro é uma iniciativa pioneira na região do alto Vale do Ribeira/alto Paranapanema, e tem atraído numerosos visitantes, principalmente dos municípios vizinhos, incluindo excursões didáticas das escolas. No entanto, a criação do Parque Natural Municipal do Morro do Ouro pode ser considerada apenas parcialmente bem sucedida porque, apesar de regularmente visitado, ainda demanda medidas essenciais para a sua completa implantação. Considera-se adequada a infraestrutura externa de recepção; mas, as medidas propostas para a o túnel T-15 ainda não foram executadas devido à indisponibilidade de recursos, comprometendo a preservação do patrimônio geológico nele contido. Também não foi realizado o mapeamento dos demais túneis para possível aproveitamento geoturístico.

Considera-se altamente relevante a preservação dos atrativos geoturísticos do PNMMO e das outras minas antigas da região, visto que a região é sabidamente carente de opções de renda. O aporte de recursos pelos turistas certamente contribuiria para 0 desenvolvimento sustentável e valorizaria a história da mineração. 
Agradecimentos: O autor agradece a Secretaria de Turismo, Cultura e Meio Ambiente que, nas pessoas de sua Secretária, Milena Alencar, da Diretora de Meio Ambiente Paula Daniel Fogaça e do Diretor do PNMMO, Francisco de Assis Ferrenha Junior, forneceram informações importantes para este artigo.

\section{Referências bibliográficas}

BRITO Neves, B.B.; CAMPOS Neto. M.C.; Fick, R.A. 1999. From Rodinia toWestern Gondwana: an approach to the Braziliano-Pan African cycle and orogenic collage. Episodes 22, 155-166.

CALAZANS, R. L. 1996. Santo Antonio das Minas de Apiahy. Gráfica Regional. São Paulo, 1996, 226 p.

CAMPANHA, G.A.C \& SADOWSKI, G.R. 1999. Tectonics of the Southern Portion of the Ribeira Belt (Apiaí Domain). Precambrian Research, 98:31-51.

CAMPANHA, G.A.C. 1991. Tectônica proterozóica no Alto e Médio Vale do Ribeira, Estados de São Paulo e Paraná. Tese de Doutorado. Instituto de Geociências, Universidade de São Paulo, 296 p.

CAMPANHA, G.A.C.; BASEI, M.A.S.; TASSINARI, C.C.G.; NUTMAN, A.P.; FALEIROS, F.M. 2008 a. Constraining the age of the Iporanga Formation with SHRIMP U-PB zircon: implications for possible Ediacaran glaciation in the Ribeira Belt, SE Brazil. Gondwana Research, 13:117-125.

CAMPANHA, G.A.C.; BASEI, M.A.S.; TASSINARI, C.C.G.; NUTMAN, A.P.; FALEIROS, F.M. 2008 b. U-Pb SHRIMP and $\mathrm{Sm}-\mathrm{Nd}$ analysis for Ribeira Belt Mesoproterozoic Neoproterozoic terranes. In: VI South American Symposium on Isotope Geology, 2008. San Carlos de Bariloche. Short Paper, Ingeis, Buenos Aires, CDROM, p. 4.

CHIODI Filho, C. 1984. Contribuição à geologia sul paulista e leste paranaense: Grupos Açungui e Setuva. In: Congresso Brasileiro de Geologia, Rio de Janeiro. 1984. Anais...Rio de Janeiro, SBG, v.5, p.2394-2406.

CPRM - Cia. de Pesquisa de Recursos Minerais. 1981. Projeto integração e detalhe geológico no Vale do Ribeira. Relatório Final. São Paulo, CPRM/SUREG-SP, $15 \mathrm{v}$.

DAITX, E.C. 1996. Origem e evolução dos depósitos tipo Perau (Pb-Zn-Ag), com base nas jazidas Canoas e Perau, Vale do Ribeira-PR. Tese de Doutorado. Instituto de Geociências, UNESP, Rio Claro, 435 p.

FALEIROS, A.M. 2012. Regimes de fluidos hidrotermais e formação de veios quartzo auríferos da mina do Morro do Ouro, Apiaí, SP. Dissertação de Mestrado, Instituto de Geociências, Universidade de São Paulo, $69 \mathrm{p}$.
FALEIROS, F.M. 2008. Evolução de terrenos tectonometamórficos da Serrania do Ribeira e Planalto Alto Turvo (SP). Tese de Doutorado. Pós-Graduação em Geoquímica e Tectônica, Instituto de Geociências, Universidade de São Paulo, 318 p.

FALEIROS, F.M.; CAMPANHA, G.A.C.; MARTINS, L.; VLACH, S.R.F.; VASCONCELOS, P.M. 2011. Ediacaran high pressure collision metamorphism and tectonics of the southerns Ribeira belt (SE Brazil): Evidence for terrane accretion and dispersion during Gondwana assembly. Precambrian Research, 189:263-291.

FASSBINDER, E. 1996. A unidade Água Clara no contexto do Grupo Açungui: um modelo transpressivo de colisão oblíqua no Neoproterozóico paranaense. Tese de Doutorado. Instituto de Geociências, Universidade de São Paulo, 207p.

HEILBRON, M.; PEDROSA-SOARES, A.C.; CAMPOS Neto, M.C.; SILVA. L.C.; TROUW, R.A.J.; JANASI, V.A. 2004. Província Mantiqueira. In: Mantesso-Neto, V.; Bartorelli, A.; Carneiro, C.D.R.; Brito-Neves, B.B. (Eds), Geologia do Continente Sul-Americano: Evolução da Obra de Fernando Flávio Marques de Almeida. Beca Produções Culurais, São Paulo, 203-234p.

PAIVA, I.P.; MORGENTAL, A. 1980. Ouro nas regiões auríferas dos Agudos Grandes e Morro do Ouro - Vale do Ribeira. Relatório final. São Paulo, CPRM/SUREGSP, $63 \mathrm{p}$.

SÁNCHEZ, L. H. 1984. Mineração ou preservação no alto vale do Ribeira/SP. Ciências da Terra, CPRM, Rio de Janeiro, 10:26-29.

SHIMADA, H. 2002. Mina do Morro do Ouro (Apiaí, SP) Um sítio potencial de visitação temática de mineração e meio ambiente. Proposta de projeto de implantação. São Paulo, 19 p (inédito).

SHIMADA, H. 2008. Mina do Morro do Ouro, Apiaí (SP) De passivo ambiental a parque. In: Congresso Brasileiro de Geologia, 44, SBG, Curitiba, 26-31/out, CD-ROM, painel e Anais, p. 399. Disponível em http://www.igeologico.sp.gov.br/downloads/poster /Shimada_2008_44CBG.pdf

SHIMADA, H.; SILVA, M. H. B. da; ROBLES, R. A.; REIS, J. M. dos. 1998. Antigas minas de chumbo-prata do Parque Estadual Turístico do Alto Ribeira (SP): estudos para recuperação e inserção no contexto do desenvolvimento sustentável. In: Congresso Brasileiro de Geologia, 40, Anais..., SBG, Belo Horizonte, p. 205. 
SIGA Junior, O.; BASEI, M.A.S.; PASSARELLI, C.R.; SATO, K.; CURY, L.F.; MCREATH, I. 2009. Lower and Upper Neoproterozoic magmatic records in Itaiacoca Belt (Paraná-Brazil): zircon ages and lithostratigraphy studies. Gondwana Research, 15:197-208.

SILVA, M. H. B. da \& SHIMADA, H. 1997. Vestiges of ancient lead-silver mining in the context of ecotouring - PETAR/Sao Paulo, Brazil. In: Wolrd Congress \& Exibition on Ecotourism. Biosfera, Rio de Janeiro, 15-18 dec., 1997. Abstracts. Biosfera, Rio de Janeiro, dec/1997, p. 130-131.

WEBER, W.; SIGA Junior, O.; SATO, K.; REIS Neto, J.M.; BASEI, M.A.S.; NUTMAN, A.P. 2004. A Formação Água Clara na região de Araçaíba-SP: registro U-Pb de uma bacia mesoproterozóica. Geologia USP - Série Científica, 4:101-110. 